\section{Predicting the Identity of Plant Invaders: Future Contributions from Horticulture}

\author{
Richard N. Mack \\ School of Biological Sciences, Washington State University, Pullman, WA 99164
}

Horticulturists have joined ecologists, conservationists, land managers and others in seeking to identity future plant invaders from amongst the vast array of species introduced into the U.S. The routine practice in horticulture of evaluating plants in field trials coupled with careful observation will serve this effort well. Most plant introductions into any new range are deliberate, and the bulk of these are motivated byhorticultural pursuits. Unlike most species introduced for soil reclamation, pastures or rangelands, horticultural introductions are intensively cultivated (e.g., irrigation, pesticide application, tillage). Cultivation simultaneously minimizes stochastic, i.e., randomly appearing, and chronic hazards for an immigrant population. Chronic hazards, such as desertic conditions for an introduced species with high water demand, will inevitably destroy the population once irrigation is withdrawn. Introduced species with such chronic limitations pose no threat of invasion. Alien species that lack a chronic limitation in a new range can nevertheless undergo extinction by random detrimental events (e.g., brief bouts of low temperatures or drought coincident with the population's introduction). The power of random events to influence a population's fate is influenced strongly by the inverse relationship between population size and the probability of local extinction. Cultivation may protect small, introduced populations through a hazardous period; the population survives and increases in size, thereby lowering the risk of its extinction. Propagules from this protected population may then spread to other sites and can eventually give rise to new, persistent populations. Horticulturists can provide invaluable information toward predicting invasions by reporting cases in which an introduced species require little, if any, cultivation to reproduce. Cases in which plants derived from an introduced population appear frequently well outside the cultivated area will be especially informative. Extermination and withdrawal from the market may be warranted for introduced species that display this second category of behavior.

The threats to national economies (Pimentel et al., 2000), the environment (Vitousek et al., 1996) and even human health (Tyler, 2004)

Received for publication 30 Oct. 2004. Accepted for publication 24 Feb. 2005. I thank Neil Anderson, Sarah H. Reichard, Judy Warnement and Peter Wharton for valuable references or advice in preparing this paper. Rich Scott once again provided skillful assistance in illustrations. I especially thank Robert Stamps and the American Society of Horticultural Science for inviting me to the 2004ASHS colloquium on plant invasiveness. posed by alien species released in new ranges are becoming increasingly apparent. For a combination of reasons, including their release from native predators, parasites and competitors, a minority of alien species can not only become naturalized, i.e., persistent, in a new range but can also proliferate, spread and consequently wreak enormous damage. Those naturalized species that display this epidemiology are termed biological invaders (Mack et al., 2000). They represent an exceedingly small minority of the alien species that arrive, but their numbers belie their negative effects (Williamson, 1996).

For the vast majority of species, including plants, dispersal in the past 500 years has been through human agencies (Ruiz and Carlton, 2003). Unlike the post-Columbian dispersal of microorganisms and insects by humans, which has been almost entirely accidental, plant species that have subsequently become naturalized were introduced largely through deliberate introductions (Groves, 1998; Mack and Erneberg, 2002). As a result, a growing fraction of the earth's flora has both a native range and an increasing introduced range. In many cases, these introduced ranges could not have been produced through natural dispersal (e.g., the mass introduction of European species to New Zealand, the introduction of Central Asian species to interior North America). The number of vascular plant species that have been introduced to North America since $1500 \mathrm{AD}$ probably cannot be determined but a conservative estimate would be approximately 40,000 taxa, based on the number of species and their varieties now commercially available in the U.S. (Isaacson, 1996). This figure dwarfs the native NorthAmerican vascularflora of approx. 18,000 species (Kartesz and Meacham, 1999).

\section{Deliberate Plant Introductions}

The overall result of these plant introductions to North America has been decidedly positive from the standpoint of human welfare. For example, the current population of the U.S. could not have been attained, much less maintained, with reliance solely on edible native U.S. plants (Mack, 1999). The fate of most alien plant species in the U.S. is either residence only within cultivation or extinction soon after introduction. The small remainder, 2500 to 3000 species, have become persistent (Karteszand Meacham, 1999) and of these species perhaps 300 species are truly invasive in the conterminous U.S. (Randall and Marinelli, 1996)

Despite the array of alien species that have been introduced outside their native range by hu- mans, most of the earth's approximately 240,000 angiosperms have no immigration history. If the collective performance of those species that have been already transported beyond their native range is any indication (and we currently have no alternative index), this large pool of potential immigrants contains taxa capable of naturalization and even invasion. The likelihood of immigration for these species obviously varies as a function of the diverse incentives among humans for transporting plants to new ranges. Although the emphasis from antiquity through the European colonial era was on transporting species for food, medicine, forage, forestry or soil stabilization (Mack, 1999, 2001; Warmington, 1974), the record of plants distributed for theirperceived ornamental value has accelerated (Mack, 1991), particularly in the last 200 years (Campbell-Culver, 2001).

Species prized as ornamentals reflecta bewildering array of human perceptions of desirable plant traits and features. These perceptions vary among and within societies, as well as within the same society over time. Some species (e.g., Aegilops cylindrica Host [bearded goatgrass]) now naturalized in the U.S. were introduced in the 19th century for dried flower arrangements. Goatgrass is an exceptionally damaging weed in cereal fields in part through its hybridization with wheat (Mack, 1991). Other naturalized species were introduced much earlier for medicinal purposes or as seasonings, e.g., Digitalis purpurea L., Taraxacum officinale Weber, and Verbascum thapsus L. These species were deliberately carried far and wide across the U.S. by early settlers (Haughton, 1978). Once introduced into temperate North America, a species often spread locally through accidental dispersal. For example, during the westward expansion of European settlers, Native Americans reputedly termed Plantago major L. white man's foot; $P$. major was to them a harbinger of approaching European settlers (Darlington, 1859).

Strong incentive remains to introduce species heretofore unknown in the U.S., despite the thousands of alien species currently available from commercial nurseries in the U.S. The public, who collectively display an enormous diversity of interest in plants, welcomes these importations. Some plant collectors specialize in morphologic groups, such as succulents or epiphytes; the desire among others is to maintain under cultivation as many species of a taxonomic group as possible (e.g., bamboos or orchids) (Mack, 2001). Much plantexploration continues a centuries old enterprise that has scoured the globe repeatedly for ornamental species that are new to the marketplace (Musgrave et al., 1999; Spongberg, 1990).

This search can inadvertently select species with features that enhance their risk to become naturalized and even invasive. For example, priority is placed on species with a long flowering time or repeated bouts of flowering, or both. Most gardeners seek species that are attractive: if not the flower, then the foliage or the fruits should have an attractive display (Mack, 2001). Attractive flowers and foliage probably impart little advantage to the likelihood of persistence in a new range, although a showy flower could be an advantage in attracting pollinators to the 
new species (Pickering, 2001). Choosing species and cultivars with large numbers of showy, fertile flowers or seeds could also increase the propagule pressure of the species. Species with attractive fruit (e.g., Hedychium gardnerianum) may have a distinct advantage in persistence because frugivorous birds are attracted to fleshy fruits, which they can disperse far from the source plant (Cuddihy and Stone, 1990).

Ease in propagation is also sought among new introductions. To this end, plant explorers sometimes peruse lists of native weeds wherever they are collecting, searching for ruderal species (low maintenance) (Anderson, 2004) that fit their other criteria (showy floral display, fleshy fruit). For instance, Cynoglossum amabile Stapf. \& J.R. Drumm., a native of southern China, is common along roadsides in its native range and has a attractive display of intense, purple flowers (RNM, personal observation). It has been introduced into the U.S. and has already become naturalized locally (Randall, 2002 and references therein).

Plant introductions to the U.S. should and will continue; the horticulture of any nation, including the U.S., could benefit from taxa that have yet to be introduced. The continuance of this free trade is protected both in U.S. trade laws governing the importation of living plant material as well as the much more recent agreements of the World Trade Organization (WTO), of which the U.S. is a signatory (FAO, 2000). However, both U.S. law and WTO agreements recognize that some alien species can be damaging and that deliberate steps must be taken to identify these species and to prevent or diminish their spread. Furthermore, the WTO requires all member nations to erect a national invasive species policy that can identify and restrict the entry of harmful plant species without imposing excessive restrictions on free trade (Shine et al., 2000). Although the U.S. bans the importation of some alien plant species under the Plant Protection Act of 2000, Public Law 106-224 (http://www.aphis.usda.gov/ppq/weeds/PPAText.PDF), these prohibitions do not address the potential risk from a vast number of species that can still be imported. The need now is to build a procedure that can rapidly screen new introductions to the U.S. and determine upon a scientific basis, a WTO requirement (Shine et al., 2000), which species constitute a risk to the importing nation. Can we erect such a flexible, rapid, science-basis screening system? The answer is a conditional "yes" (National Research Council, 2002), and I contend for the reasons that follow that the horticulture industry is in a particularly good position to provide essential information needed to devise this procedure.

\section{Predicting the Identity of Invasive Species: Attributes and Climate Matching}

Predicting which species could become invasive amongst potentially tens of thousands of introductions into any new range is a daunting task and includes statistical hurdles that may not be immediately apparent (Lonsdale and Smith, 2001). Comparatively few species are legitimate concerns and should be barred entry. Identifying this distinct minority has been a goal of biologists even before the establishment of plant quarantine lists (Gray, 1879). As a first approximation to prediction, biologists often search for correlation between invasive species and traits or attributes of their biology (e.g., no seed dormancy, long flowering periods, evergreen leaves) (Reichard and Hamilton, 1997). This approach is eminently reasonable: a species with attributes that enhance its ability to survive in a new environment could serve as a guide to the performance of other species with the same attribute(s).

The record of these investigations as predictors of potentially invasive species is however mixed. In some cases, the link appears strong. Rejmanek and Richardson (1996) find a strong correlation between the persistence of some pines in South Africa and these same pines' animal-dispersed seeds. Similar successes have been reported for larger, unrelated groups of species, including invasive species in Hawaii (Daehler et al., 2004) and woody species in the U.S. (Reichard and Hamilton, 1997). The problems with sole reliance on attribute-based systems are evident in their inability, so far, to satisfactorily screen all introductions. For instance, the high level of false positives (i.e., species declared invasive when in fact they are not) (Lonsdale and Smith, 2001; Reichard and Hamilton, 1997) runs afoul of international rules minimizing restrictions on free trade (Shine et al., 2000). These limitations further suggest that information beyond a species' attributes is needed to predict its fate in a new range. Species' attributes are nevertheless part of the equation needed to develop a comprehensive system for predicting invasive species.

Another common sense approach for predicting the identity of future invasive species employs comparisons between the climate of the immigrant species' native (or other donor) range with the climate in a potential recipient locale (Kriticos and Randall, 2001). Climate is often the strongest single deterrent of a species' range (Woodward, 1987). In fact, so strong is the link between climate and plant distribution that climatologists long ago adopted the names of some widespread vegetation types (e.g., steppe, tundra) for the corresponding climatic regions (Trewartha, 1968, p. 241). In the last 20 years computer software, such as CLIMEX (Sutherst et al., 1998), has been developed to predict locales where an alien species could survive, based on similarities in the climates of donor and recipient ranges (Holt and Boose, 2000; Kriticos et al., 2003). No comparable system has been developed however to encapsulate and compare the biotic aspects (e.g., predation, competition and parasitism) among environments. This biological information is needed because a native species in the potential new rage can single-handedly prevent naturalization (Mack, 1996).

If a species' naturalization and eventual invasion depended strictly on a list of its attributes or its tolerance of the climate in the new range, or both, the outcome of any immigration would be predictable. To an unknown extent however a species may go through recurring immigrations into a new locale before eventually persisting (Mack, 1995; Sax and Brown,
2000; Veltman et al., 1996). Such cases suggest that other factors contribute to immigrants' fate beyond their attributes and tolerance of the local climate. Certainly such outcomes may reflect low genetic variation among the immigrants (Newman and Pilson, 1997). But even the fates of different genotypes do not fully explain the apparent randomness with which some species eventually become naturalized in a new range. Other important factors, such as the size of the immigrant population(Berggren, 2001; Veltman et al., 1996) and especially the character of the randomness or stochasticity of the environment in the new range, could also explain these varied outcomes (Drake and Lodge, 2004). I contend that prediction of the response of immigrant populations to environmental stochasticity and especially the role we humans play in buffering this stochasticity are essential parts of the predictive framework for identifying which species, amongst so many, will not only become naturalized but even invasive.

\section{The size of Immigrant Populations and Environmental Stochasticity}

It is a most optimistic gardener who plants a single seed in a new location with the expectation that this sole individual will survive and multiply. Sowing multiple seeds or planting multiple cuttings of a species is implicit recognition that a plant's fate can vary enormously from point to point, even in the same small locale (Harper, 1977, p. 123). Abundant theory in population biology supports any gardener's experience and practice. Even for a population of genetically identical individuals, the larger the population (Belovsky et al., 1999) and the more patches in which they occur (Bascompte et al., 2002), the more likely some individuals will produce progeny. This correlation between survival and population size is important here because an immigrant populations may be small, even if deliberately introduced (Mack, 1995). For any species in an environment within its ecological amplitude there is a minimum viable population (MVP) that must be maintained for persistence (Simberloff, 1988).

The random expression of most facets of the environment further works against any individual plant's survival. For example, weather is the random expression of the amplitude in climate. Accurately predicting the weather at a site is exceedingly difficult, even for short periods (Allaby, 2002), and weather is but one aspect of environmental stochasticity. The magnitude of this stochasticity, which translates into uncertainty about the conditions for plant growth or even survival, encompasses not just the physical environment but also biotic forces, such as grazers, predators, and parasites (Mack and Pyke, 1984).

The hazards of environmental stochasticity are acute for small, alien populations because these populations may be reduced rapidly and may be unlikely to receive new immigrants. As a result, such populations may not recover from deleterious events in environmental stochasticity, except under subsequent (and 
extraordinarily) favorable conditions (Lande, 1993; Simberloff, 1988). Although the odds for persistence often appear very low, they are still finite. Populations can become established strictly through chance alone, i.e., these populations beat the long odds imposed through random events in the environment (Ridley, 1930). Are naturalized floras then simply the product of these long odds or is another factor affecting and even increasing the odds in favor, even temporarily, of plant survival and population persistence?

\section{The Role of Cultivation}

Cultivation has multiple definitions to which I will add one more: a buffer against the hazards imposed by environmental stochasticity. Cultivation can take many forms (tillage, irrigation, insecticide application), and many of these tasks illustrate the role cultivation plays in protecting an immigrant population from stochastic events. In these cases, cultivation insulates plant populations, including populations of ornamental plants, from vagaries of the environment that they might numerically withstand if the populations were sufficiently large. In contrast, protecting a species in locales where it faces a chronic hazard, e.g., the maintenance of cotton under irrigation in the American Southwest (Erie et al., 1981), is also cultivation but any environmental stochasticity is irrelevant for plant survival. In these cases, all members of the alien population die as soon as cultivation is withdrawn.

Cultivation applied during periods of highrisk for an immigrant population provides an essential service. It can indefinitely maintain a seed or propagule source in the new range. As a result, there is an opportunity that some seeds, bulbils or plantlets produced under cultivation will establish a new population outside cultivation. In time, multiple foci of the immigrant population may arise in the new range, all either direct descendants of plants still under cultivation or descendants of these new foci (Fig. 1). In this manner a species can become naturalized (Mack, 1995, 2000). Thus, the likelihood of naturalization is substantially enhanced by the maintenance of a deliberately introduced founder population under cultivation. This scenario contrasts with the very low likelihood of naturalizations arising from repeated accidental immigrations, which may be infrequent and for which the immigrants themselves are at high risk of extinction without cultivation.

The link between cultivation and naturalization as described here helps explain the strong correlation between deliberately introduced species and naturalizations (Mack, 2000). Two-thirds of the naturalized flora in the U.S. are likely comprised of species that were deliberately introduced (Mack and Erneberg, 2002). Another much smaller fraction are seed contaminants in crop seeds that have undergone strong selection, such that their biology strongly mimics the crop's biology (e.g., seed size, color, and dormancy as well as

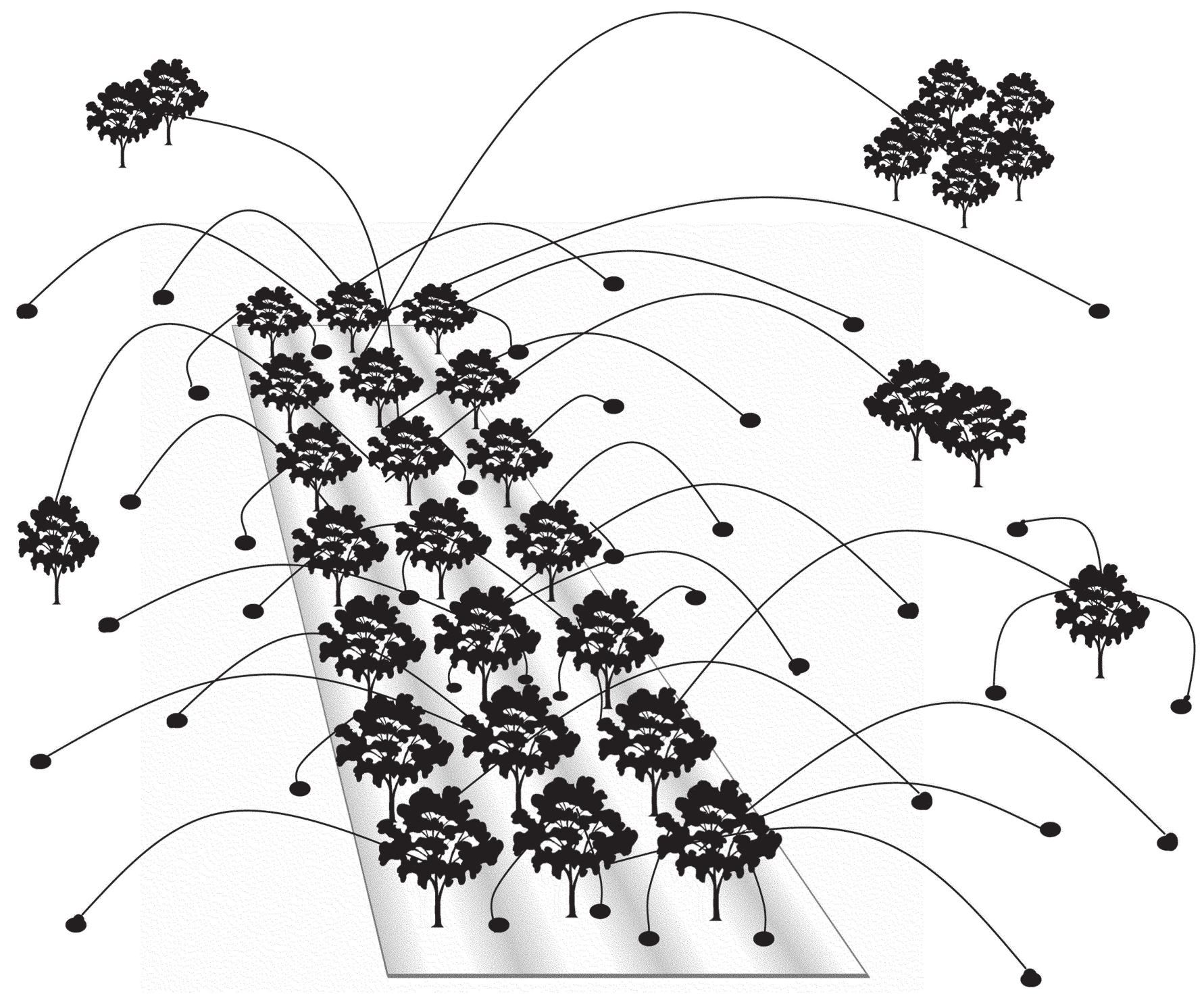

Fig. 1. An alien population under cultivation is buffered indefinitely from much environmental stochasticity that would otherwise destroy it. As a result, the population routinely produces seeds that are dispersed. Some of these seeds eventually give rise to new populations that foster further spread; most however fail to produce new populations (black circles). 
plant phenology, even height and appearance) (Barrett, 1983; Mack and Erneberg, 2002). Few species that are deliberately introduced are simply sown without accompanying cultivation (e.g., species introduced in arid rangelands and soil stabilization), and these species are likely sown in huge founder populations that increase their likelihood of persistence. In contrast, cultivation for ornamental species is often intensive. As beneficiaries of cultivation, the founder populations of these species have subsequently given rise to many naturalizations
(Mack, 1999, 2000). In summary, the likelihood of naturalization appears to increase greatly with deliberate transport and cultivation. The following examples provide evidence that these forces can facilitate the emergence of ornamental species as invaders.

\section{Ornamental Species that became Invaders}

Garden escapes, i.e., plants that arose from seeds or propagules that dispersed from a gar- den, are widely observed (Clement and Foster, 1994). Botanical gardens have provided some of the best-documented examples in which an alien species has escaped, spread and given rise to an invasion. Botanical gardens often maintain alien plants that are not in general commerce, thus greatly narrowing the list of likely introduction points for any newly detected alien species found nearby. Furthermore, the garden's conservators are likely to detect escapes in the course of monitoring the garden's boundary for pests.

\section{Senecio Squalidus $L$. \\ Oxford Ragwort}

- First Recorded before 1900

- All other records

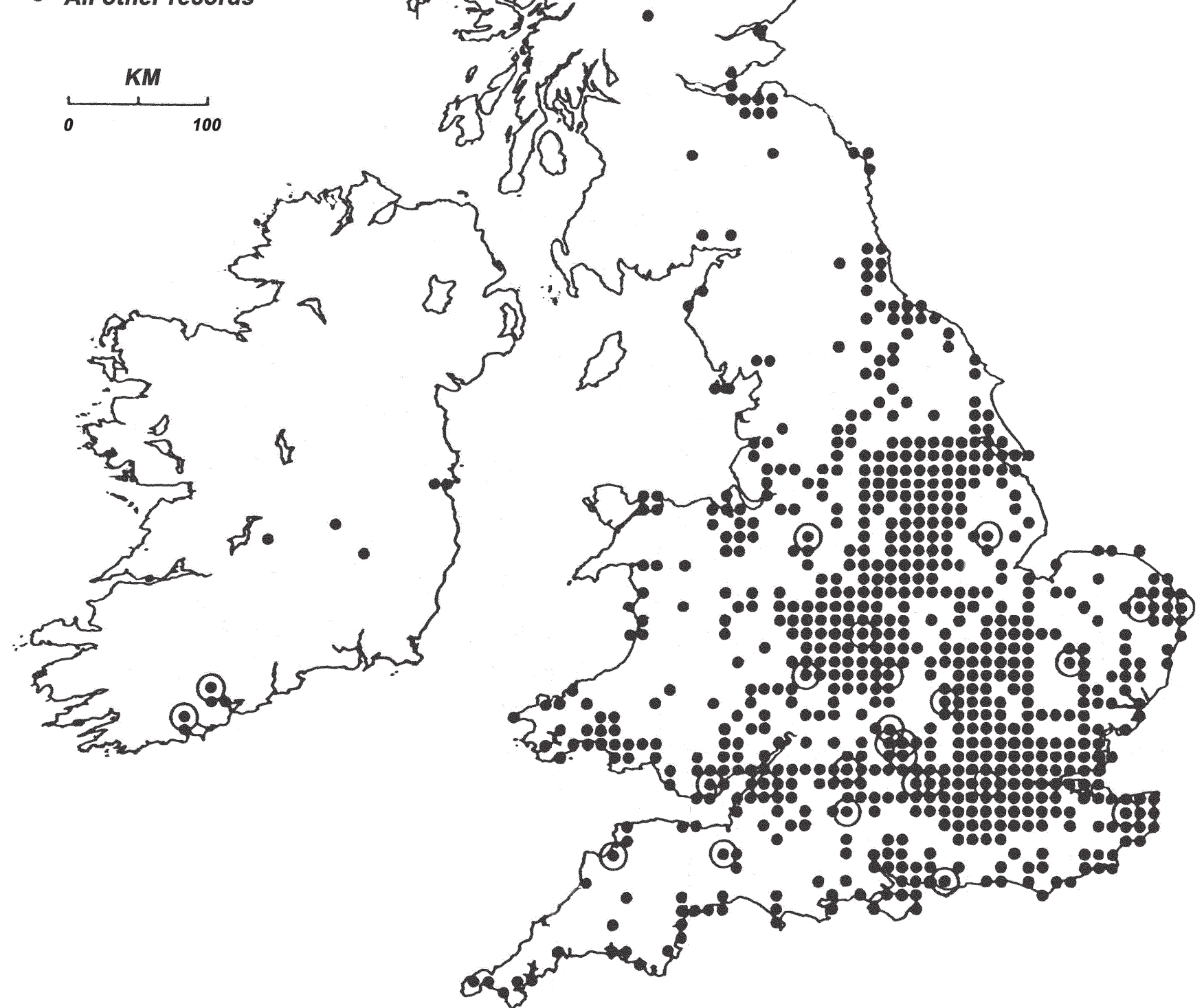

Fig. 2. Senecio squalidus spread from cultivation in the Oxford University Botanic Garden before 1800 and is now found commonly across much of Great Britain (Perring and Walters, 1976). 
Mimosa pigra L. (mimosa) is a tall shrub to small tree native to tropical America. It has long been deemed an attractive species for tropical gardens and was planted widely throughout tropical and subtropical Africa (Bentham, 1875), a practice that continues sporadically (B \& T World Seeds, Aigues-Vives, France. http://www.b-and-t-world-seeds.com). In tropical Asia and Oceania it is an aggressive invader, which has resisted most attempts at control. Mimosa's greatest damage so far has probably been inflicted within floodplains in the Northern Territory of Australia where it has largely transformed a native treeless floodplain vegetation into a mimosa monoculture (Braithwaite et al., 1989 and references therein).

The circumstances of its introduction into the Northern Territory at Darwin are not altogether clear, but in the most plausible explanation it first appeared at the Darwin Botanical Garden late in the 19th century. By logically eliminating other possibilities, Miller and Lonsdale (1987) deduced that M. pigra was likely the noxious mimosa being combated in the garden by 1914. A photograph taken on the garden grounds in 1936 shows the shrub growing unattended in a watercourse (Miller and Lonsdale, 1987). The strongest circumstantial evidence indicates that a cultivated founder population of the tree resided in Darwin and was the source for its accidental spread into the Adelaide River. From this point of entry, the shrub spread to dominate about 45,000 ha in the riparian landscape south of Darwin.

As the epidemiology of Mimosa pigra illustrates, direct observation of an alien species' initial escape(s) and subsequent spread from cultivation is usually not noted. The first few occurrences of a species outside cultivation would usually not attract attention, except in areas where collection intensity is extraordinarily intense. The classic account assembled by Kent (1956, 1960, 1964a, 1964b, 1964c) of the escape and subsequent spread of Senecio squalidus L. (Oxford ragwort) from the Oxford University Botanic Garden in Great Britain further substantiates concerns that cultivated alien species can indeed radiate far from a cultivated founder population and eventually establish self-sustaining foci of invasion.

Oxford ragwort is a native annual/perennial of Sicily (Abbott et al., 2000) and was growing in the university's garden by 1690 . The first record of its appearance outside the garden was in 1794 by Smith, and by 1800 the same collector reported it "as very plentiful on almost every wall in Oxford," which suggests that it had escaped much earlier (Smith, 1799 as cited in Kent, 1956). The post-1800 collection records for $S$. squalidus are extensive and permit construction of a detailed chronology of the species' spread away from Oxford, especially along the developing railroad system (Kent, 1956). The pappus of the plant's dried fruit greatly aided in its aerial spread. Much greater dispersal was achieved as the species spread along rail lines and in railcars. Druce (1927) reports seeing the fruit remaining suspended in the air in a rail carriage from Oxford to Tilehurst (about $40 \mathrm{~km}$ away) in 1879. Accidental transport continued for the next 60 years, so that by 1940 the species was naturalized along many rail lines throughout southern England and adjacent Wales (Kent, 1956; 1960). It had not however penetrated into the countryside away from rail lines, except where deliberately introduced.

The distribution pattern of $S$. squalidus changed during World War II, as the plant was carried in the rubble from war-devastated walls and buildings and dumped into gravel pits. This rubble-strewn habitat proved ideal for its further establishment (Kent, 1964a, 1964b). By the late 1950s, the alien had reached the Tyne Valley about $300 \mathrm{~km}$ north of its initial point of escape from cultivation (Kent, 1964c). Spread accelerated after 1960, such that it occurred throughout much of southern England by 1976 (Perring and Walters, 1976) (Fig. 2). Today Oxford ragwort is found throughout the southern two-thirds of England, plus many locales in Scotland, Wales and Ireland (Preston et al., 2002).

Several episodes in the early history of $S$. squalidus in southern England reveal the role that cultivation can contribute to eventual naturalization. The taxon had apparently been maintained in the Oxford Botanic Garden for about 100 years before escapes were detected. At least two nonmutually exclusive explanations could account for this prolonged delay. First, S. squalidus arose through the hybridization of two ancestral species in Sicily. Once in Oxford, the immigrant population was isolated from its parents, and its genotype became fixed through segregation, recombination and possible mutation to yield the genotype that escaped cultivation (Abbott et al., 2000). Admittedly, earlier escapes may have been overlooked. This explanation seems unlikely however, given the intense collecting activity in Oxford, even in the 18th century (Clokie, 1964). An alternative explanation holds that seeds of $S$. squalidus had been dispersed from the garden throughout the 18th century but had consistently failed to produce a persistent population. The random appearance of circumstances conducive for establishment of new populations did not occur until about 1800 . Further evidence that small populations of $S$. squalidus are vulnerable to stochastic events is provided by Turrill (1948), who failed to establish the species through transplants and fruits on walls at Woodstock (about $10 \mathrm{~km}$ northwest of Oxford). These immigrants were extirpated, even when deliberately transported to an apparently suitable habitat. Each new focus of $S$. squalidus appears to have been dependent on the population reaching sufficient size that it could withstand local environmental stochasticity without cultivation.

Escapes of alien species continue. The 1980 Sino-American Botanical Expedition to the Shennongjia Forest District in Hubei Province, China, collected a trove of species new to science as well as many species of horticultural interest (Dosmann and Del Tredici, 2003). Many of these species were distributed to botanical gardens in North America, including the Botanical Garden of the University of British Columbia in Vancouver. Among the Chinese accessions cultivated in the garden in
Vancouver was the shrub Rubus simplex Focke, which produces a dense mat-like stoloniferous layer that retards the growth of other species. More worrisome are its fleshy yellow fruits that are spread locally by birds. By the early 1990 s, the shrub was appearing with increasing frequency on the grounds of the garden. For the last 10 years the garden staff has conscientiously destroyed this perennial within the garden. Although the Botanical Garden is not entirely rid of $R$. simplex, this goal will likely be achieved in the next few years. Fortunately, the staff noted its spread and took prompt action to remove the source plants and eradicate all the escapes. Nevertheless, "it almost got away" (P. Wharton, personal communication).

\section{Horticulture's Contribution to a Predictive Framework}

Predicting the identity of future invasive species will require integrating our knowledge of each species' attributes that contribute to its persistence within a climatic region as well as gauging the environmental stochasticity in the new range. Progress in identifying relevant attributes will continue, even if these attributes are detected retrospectively (Daehler et al., 2004). Climate matching will likely become more discriminating among locales (Pauchard et al., 2004). The biggest challenge will be assembling a comprehensive understanding of regional environmental stochasticity and the cultivation needed to buffer alien species from these forces (Mack, 2000; Minton, 2003). To meet this challenge, risk assessment will need to go beyond reliance on our current understanding of the traits of a species and its performance elsewhere as illustrated in the Voluntary Code of Conduct for Nursery Professionals (http://www.centerforplantconservation.org/invasives/nurseryN.html) and include experimental evaluations, i.e., field trials, of species in their potential new ranges.

Horticulture, especially ornamental horticulture, can provide much of this needed information through its emphasis on field trials for recently introduced alien species. As new species are introduced to the U.S. for commercial evaluation, I recommend that information on plant performance under two categories be systematically collected and widely shared.

Two categories of information are needed from field trials.

Identifying species that require little or no cultivation. Attention should be paid to the mode (irrigation, tillage, pesticide application, frost protection, minimum nutrient requirements), frequency and duration of cultivation needed for recent plant introductions to persist through sexual reproduction or vegetative propagation in field trials. Special attention should be placed on those species that require little or no cultivation, as these species could conceivably become established in the new range. I recommend that these species continue to be grown in trials, while simultaneously adding them to a watch list among nurseries and other horticulturists in the region.

Identifying and reporting species that 
routinely escape cultivation. Heightened attention should be placed on species that routinely escape from garden trials and give rise to reproducing or vegetatively propagating plants at sites beyond cultivation. Although most of these species will reside only as transients in the new range, some could become naturalized. These species should be reported to the state's plant pest council or equivalent (e.g., www.caleppc.org; www.se-eppc.org; invasives.eeb.uconn.edu/ipane). These species could continue to be on a watch list, although the more conservative approach would be to destroy the founder population as well as the garden escapes and discourage further trials with the species in the region. This course of action should be reserved for cases in which the species is routinely appearing as an escape over the course of several consecutive years and establishing outside the garden. Withdrawing such a species from further commercial evaluation should be voluntary and on a case-by-case basis but will be justified in some cases.

Horticultural escapes have provided a majority of the naturalized flora of the U.S. (Mack and Erneberg, 2002) from which many invasive species have subsequently emerged (Randall and Marinelli, 1996). This legacy need not however serve as prophecy for future plant invasions. Gardens can become instead an invaluable tool in the early detection of those species that need careful evaluation for their potential to invade. In reality, most species evaluated in garden trials will prove harmless in their new locales; they will either not survive outside the bounds of cultivation or will produce only the occasional escapee that soon perishes without producing progeny. The need here is to identify the small minority that requires little or no cultivation and has a propensity to proliferate and spread in the new range.

I envision horticulturists in general and the plant nursery industry in particular providing an essential service in the future as the early detectors of potentially invasive species. Many commercial growers have established test gardens in radically different climates across the U.S. For example, Monrovia Nursery (Azusa, Calif.) maintains six widespread nurseries in the U.S. to evaluate and produce plants for different climatic zones (http://www.monrovia. com). Across the U.S. thousands of commercial and private nurseries collectively span almost all climatic and soil regions. Whether large integrated networks of nurseries, such as those owned by Monrovia Nursery, or much more modest operations, these gardens are in effect a basis already in place to evaluate alien species for the likelihood of escape from cultivation.

The type of voluntary system I envision here contains strong incentives. No responsible horticulturist or amateur gardener wants to contribute to the nation's invasive flora (Reichard and White, 2001). Whether informally as private parties or more formally in horticultural and growers' associations, those who evaluate alien plants for commerce have a great opportunity. They can contribute in what is already a national mandate (National Research Council,
2002) - the erection of a rapid, comprehensive, predictive framework for invasive species that is transparent, effective and imposes minimum constraint on the importation and commercial distribution of plants.

\section{Literature Cited}

Abbott, R.J., J.K. James, J.A. Irwin, and H.P. Comes. 2000. Hybrid origin of the Oxford ragwort, Senecio squalidus L. Watsonia 23:123-138.

Allaby, M. 2002 (ed.). Encyclopedia of weather and climate. Facts on File, New York.

Anderson, N. 2004. Invasive horticultural crops. Part 2: Where do they come from? Minn. Land Assn. News 28(4):28-33.

Barrett, S.C.H. 1983. Crop mimicry in weeds. Econ. Bot. 37:255-282.

Bascompte, J., H. Possingham, and J. Roughgarden. 2002. Patchy populations in stochastic environments: critical number of patches for persistence. Amer. Natur. 159:128-137.

Belovsky, G.E., C. Mellison, C. Larson, and P.A. Van Zandt. 1999. Experimental studies of extinction dynamics. Science 286:1175-1177.

Bentham, G. 1875. VII. Revision of the suborder Mimoseae. Trans. Linn. Soc. London 30:335-664.

Berggren,A. 2001. Colonization success in Roesel's bush-cricket Metrioptera roeseli: The effects of propagule size. Ecology 82:274-280.

Braithwaite, R.W., W.M. Lonsdale and J.A. Estbergs. 1989. Alien vegetation and native biota in tropical Australia: The spread and impact of Mimosa pigra. Biol. Conser. 48:189-210.

Campbell-Culver, M. 2001. The origin of plants: the people and plants that have shaped Britain's garden history since the year 1000 . Headline, London.

Clement, E.J. and M.C. Foster. 1994. Alien plants of the British Isles. Bot. Soc. Brit. Isles, London.

Clokie, H.N. 1964. An account of the herbaria of the Department of Botany in the University of Oxford. Oxford Univ. Press, London.

Cuddihy, L.W. and C.P. Stone. 1990. Alteration of native Hawaiian vegetation. Effects of humans, their activities and introductions. Coop. Natl.Park Resour. Studies Unit, Univ. Hawaii, Manoa.

Daehler, C., J.S. Denslow, S. Ansari, and H.C. Kuo. 2004. Arisk-assessment system for screening out invasive pest plants from Hawaii and other Pacific Islands. Conserv. Biol. 18:360-368.

Darlington, W. 1859. American weeds and useful plants. 2nd ed. (revised by G. Thurber). A.O Moore, New York.

Dosmann, M. and P. Del Tredici. 2003. Plant introduction, distribution, and survival: A case study of the 1980 Sino-American botanical expedition. BioScience 53:588-597

Drake, J.M. and D.M. Lodge. 2004. Effects of environmental variation on extinction and establishment. Ecology Letters 7:26-30.

Druce, G.C. 1927. The flora of Oxfordshire. 2nd ed. Oxford.

Erie, L. J., O. F. French, D. A. Bucks, and K. Harris. 1981. Consumptive water use of water by major crops in the southwestern United States. USDA Conserv. Res. Rpt. 29.

Food and Agriculture Organization of the United Nations. 2000. Multilateral trade negotiations on agriculture: A resource manual. vol. 3. SPS and TBT agreements. FAO, Rome.

Gray, A. 1879. The pertinacity and predominance of weeds. Amer. J. Sci. Arts 18:161-167.

Groves, R.H. 1998. Recent incursions of weeds to Australia. Coop. Res. Ctr. Weed Mgt. Systems Tech. Ser. 3. Adelaide, Australia.

Harper, J.L. 1977. Population biology of plants. Academic Press, London.
Haughton, C.S. 1978. Green immigrants. The plants that transformed America. Harcourt Brace Jovanovich, New York.

Holt, J.S. and A.B. Boose. 2000. Potential for spread of Abutilon theophrasti in California. Weed Sci. 48 (1):43-52.

Isaacson, R.T. (ed.). 1996. Andersen horticultural library's source list of plants and seeds. 4th ed. Andersen Hort. Library, Univ. Minn., Minneapolis.

Kartesz, J.T. and C.A. Meacham. 1999. Synthesis of the North American flora. North Carolina Botanical Garden, University of North Carolina, Chapel Hill.

Kent, D.H. 1956. Senecio squalidus in the British Isles-1, early records (to 1877). Bot. Soc. Brit. Isles Proc. 2:115-118.

Kent, D.H. 1960. Senecio squalidus in the British Isles-2, The spread from Oxford (1879-1939). Bot. Soc. Brit. Isles Proc. 4:375-379.

Kent, D.H. 1964a. Senecio squalidus in the British Isles-4, Southern England (1940 $\rightarrow$ ). Bot. Soc. Brit. Isles Proc. 5:210-213.

Kent, D.H. 1964b. Senecio squalidus in the British Isles-5, The Midlands $(1940 \rightarrow)$. Bot. Soc. Brit. Isles Proc. 5:214-216.

Kent, D.H. 1964c. Senecio squalidus in the British Isles-6, Northern England $(1940 \rightarrow)$. Bot. Soc. Brit. Isles Proc. 5:217-219.

Kriticos, D. J. and R. P. Randall. 2001. A comparison of systems to analyze potential weed distributions, p. 61-79. In: R.H. Groves, F.D. Panetta, and J.G. Virtue (eds.). Weed risk assessment. CSIRO, Collingwood, Australia.

Kriticos, D.J., R.W. Sutherst, J.R. Brown, S.W. Adkins, G.F. Maywald. 2003. Climate change and the potential distribution of an invasive alien plant: Acacia nilotica ssp. indica in Australia. J. Appl. Ecol. 40:111-124.

Lande, R. 1993. Risks of population extinction from demographic and environmental stochasticity and random catastrophes. Amer. Nat. 142(6):911-927.

Lonsdale, W.M. and C.S. Smith. 2001. Evaluating pest-screening systems - Insights from epidemiology and ecology. p. 52-60. In: R.H. Groves, F.D. Panetta, and J.G. Virtue (eds.). Weed risk assessment. CSIRO, Collingwood, Australia.

Mack, R.N. 1991. The commercial seed trade: an early disperser of weeds. Econ. Bot. 45:257-273.

Mack, R.N. 1995. Understanding the processes of weed invasions: the influence of environmental stochasticity, p. 65-73. In: C.H. Stirton (ed.). Weeds in a changing world. Brighton, U.K.

Mack, R.N. 1996. Biotic barriers to plant naturalization, p. 19-26. In: V.C. Moran and J.H. Hoffman (eds.). Proceedings of the IX International Symposium on Biological Control of Weeds. Univ. Cape Town, South Africa.

Mack, R.N. 1999. The motivation for importing potentially invasive plant species: a primal urge? p. 557-562. In: D. Eldridge and D. Freudenberger (eds.). People and rangelands: building the future. Proc. VI Intl. Rangeland Congress, Townsville, Australia.

Mack, R.N. 2000. Cultivation fosters plant naturalization by reducing environmental stochasticity. Biol. Invasions 2:111-122.

Mack, R.N. 2001. Motivations and consequences of the human dispersal of plants, p. 23-34. In: J.A. McNeely (ed.). The great reshuffling: human dimensions in invasive alien species. IUCN, Gland, Switzerland, and Cambridge, U.K.

Mack, R.N. and D. A. Pyke. 1984. The demography of Bromus tectorum: The role of microclimate, predation and disease. J. Ecol. 72:731-748.

Mack, R.N. and M. Erneberg. 2002. The United States naturalized flora: Largely the product of 
deliberate introductions. Mo. Bot. Gard. Ann. 89:176-189.

Mack, R.N., D. Simberloff, W.M. Lonsdale, H. Evans, M. Clout, and F.A. Bazzaz. 2000. Biotic invasions: causes, epidemiology, global consequences and control. Ecol. Appl. 10:689-710.

Miller, I.L. and W.M. Lonsdale. 1987. Early records of Mimosa pigra in the Northern Territory. Plant Prot. Q. 2(3):140-142.

Minton, M.S. 2003. Plant naturalization: surviving the gauntlet of environmental stochasticity. PhD diss. Wash. State Univ., Pullman.

Musgrave, T., C. Gardner, and W. Musgrave. 1999. The plant hunters. Seven Dials, Cassell, London.

National Research Council. 2002. Predicting invasions by nonindigenous plants and plant pests. Natl. Acad. Sci., Wash., D.C.

Newman, D. and D. Pilson. 1997. Increased probability of extinction due to decreased genetic effective population size: experimental populations of Clarkia pulchella. Evol. 51:354-362.

Pauchard, A., L.A. Cavieres, and R.O. Bustamante. 2004. Comparing alien plant invasions among regions with similar climates: Where to from here? Diversity \& Distributions 10:371-375.

Perring, F.H. and S.M. Walters. (eds.). 1976. Atlas of the British flora. 2nd ed. EP Publ. Bot. Soc. Brit. Isles, Wakefield, U.K.

Pickering, C.M. 2001 Size and sex of floral displays affect insect visitation rates in the dioecious Australian alpine herb, Aciphylla glacialis. Nord. J. Bot. 21 (4):401-409.

Pimentel, D., L. Lach, R. Zuniga, and D. Morrison.
2000. Environmental and economic costs of nonindigenous species in the United States. BioSci. 50 (1):53-65.

Preston, C.D., D. Pearman, and T.D. Dines. 2002. New atlas of the British \& Irish flora: an atlas of the vascular plants of Britain, Ireland, the Isle of Man and the Channel Islands. Oxford Univ. Press, Oxford.

Randall, J.M. and J. Marinelli. (eds.). 1996. Invasive plants: Weeds of the global garden. Brooklyn Bot. Garden, Brooklyn.

Randall, R.P. 2002. A global compendium of weeds. R.G. and F.J. Richardson, Melbourne, Australia.

Reichard, S.H. and C.W. Hamilton. 1997. Predicting invasions of woody plants introduced into North America. Conser. Biol. 11:193-203.

Reichard, S.H. and P. White. 2001. Horticulture as a pathway of invasive plant introductions in the United States. BioSci. 51:103-113.

Rejmanek, M. and D.M. Richardson. 1996. What makes some plant species more invasive? Ecology 77:1655-1661.

Ridley, H. N. 1930. The dispersal of plants throughout the world. L. Reeve, Ashford, Kent, U.K.

Ruiz, G.M. and J.T. Carlton. 2003. Invasion vectors: A conceptual framework for management, $p$. 459-504. In: G.M. Ruiz and J.T. Carlton (eds.). Invasive species. Vectors and management strategies. Island Press, Wash., D.C.

Sax, D.F. and J.H. Brown. 2000. The paradox of invasion. Global Ecol. Biogeog. 9 (5):363-371.

Shine, C., N. Williams, and L. Gündling, L. 2000. A guide to designing legal and institutional frameworks on alien invasive species. IUCN, Gland, Switzerland, and Cambridge, U.K.

Simberloff, D. 1988. The contribution of population and community biology to conservation science. Annu. Rev. Ecol. Syst. 19:473-511.

Spongberg, S.A. 1990. A reunion of trees: The discovery of exotic plants and their introduction into North American and European landscapes. Harvard Univ. Press, Cambridge.

Sutherst, R.W., G.F. Maywald, T. Yonow, and P.M. Stevens. 1998. CLIMEX. Predicting the effects of climate on plants and animals. User guide. CSIRO, Melbourne, Australia.

Trewartha 1968. An introduction to climate. 4th ed. Mc-Graw-Hill, New York.

Turrill, W.B. 1948. British plant life. London, Collins.

Tyler, K.L. 2004. West Nile virus infection in the United States. Arch. Neurol. 61(8):1190-1195.

Veltman, C.J., S. Nee, and M.J. Crawley. 1996. Correlates of introduction success in exotic New Zealand birds. Amer. Nat. 147 (4):542-557.

Vitousek, P.M., C.M. D'Antonio, L.L. Loope, and R.G. Westbrooks. 1996. Biological invasions as global environmental change. Amer. Sci. 84:468-478.

Warmington, E.H. 1974. The commerce between the Roman empire and India. Curzon, London.

Williamson, M. 1996. Biological invasions. Chapman \& Hall, London.

Woodward, F.I. 1987. Climate and plant distribution. Cambridge Univ. Press, Cambridge, U.K. 